\title{
LETRAMENTO, DISCURSO E GRAMÁTICA FUNCIONAL
}

\author{
(Literacy, discourse and functional grammar)
}

\author{
Guilherme Rios ${ }^{1}$ \\ (Universidade de Brasília - UnB/NELiS)
}

\begin{abstract}
This essay aims at providing a proposal of theorizing on the interface between literacy, discourse and functional grammar, through the selection of the Social Theory of Literacy (Barton \& Hamilton, 1998; 2000), in the New Literacy Studies, Critical Discourse Analysis (Fairclough, 1992; Chouliaraki \& Fairclough, 1999) and Systemic Functional Linguistics (Halliday, 1994). It sets out from a discussion on the possibility of integration between the fields of literacy and discourse and carries on towards a dialogue with ethnography and functional grammar. At the end, some implications of this proposal for discourse and ethnography based literacy research are presented.
\end{abstract}

Key-words: New Literacy Studies; The Social Theory of Literacy; Critical Discourse Analysis; Ethnography; Systemic Functional Linguistics.

\section{RESUMO}

Este ensaio visa a oferecer uma proposta de teorização na interface entre letramento, discurso e gramática funcional, selecionando a Teoria Social do Letramento (Barton e Hamilton, 1998; 2000), nos Novos Estudos do Letramento, a Análise de Discurso Crítica (Fairclough, 1992; Chouliaraki e Fairclough, 1999) e a Linguística Sistêmico-Funcional (Halliday, 1994). Inicia-se com uma discussão acerca da possibilidade de integração entre os campos do letramento e do discurso e progride na direção de um diálogo com a etnografia e a gramática funcional. Ao final, são apresentadas algumas implicações dessa proposta para a pesquisa sobre o letramento

1. Pesquisador Colaborador junto ao Programa de Pós-Graduação em Linguística e membro do Núcleo de Estudos de Linguagem e Ideologia (NELiS/CEAM) da $\mathrm{UnB}$, tem diversas publicações sobre letramento, no Brasil e no exterior. 
baseada no discurso e na etnografia, ou do discurso em relação ao letramento.

Palavras-chave: Novos Estudos do Letramento; Teoria Social do Letramento; Análise de Discurso Crítica; Etnografia; Linguística SistêmicoFuncional.

\section{Introdução: letramento e discurso}

Em grande medida, os Estudos do Letramento podem ser integrados à Análise do Discurso. Isso remonta ao ponto de Brian Street (1993: 12, 1995: 162) em que uma associação entre a análise do discurso no interior da linguística e algumas abordagens etnográficas na antropologia, as quais "façam uma consideração mais profunda de teorias do poder e da ideologia", poderiam ser produtivas para dar sequência aos desenvolvimentos nos estudos relacionados a ambas as áreas.

Uma das primeiras referências na associação entre os conceitos de 'letramento' e de 'discurso' é James Gee (1990). Conforme o autor, "é somente dentro do contexto da noção de Discurso que podemos alcançar uma definição viável de 'letramento' (p. 150). Gee define Discurso como "uma associação socialmente aceita entre modos de usar a língua, de pensar, sentir, acreditar, valorar e de atuar que podem ser usadas para identificar-se como um membro de um grupo ou uma rede 'social' socialmente significativa, ou sinalizar (que alguém está desempenhando) um 'papel' socialmente significativo" (p. 143).

Baynham (1993, 1995) é outra referência na integração entre os campos do letramento e do discurso. Este autor defende uma abordagem do letramento como linguagem na prática social (1995: 245) e refere-se à Análise de Discurso Crítica (ADC), com base em Kress (1989) e em Fairclough (1989). Baynham resenhou vários conceitos de 'discurso', como foram utilizados pelos linguistas no passado sequências mais extensas da língua, tanto falada como escrita - e no sentido de Kress (1989: 7) - 'séries de declarações sistematicamente 
organizadas que dão expressão aos significados e valores de uma instituição’ - em uma lista dentre outros conceitos-chave para uma compreensão mais profunda do letramento como prática social. Baynham utiliza o termo 'discursos' de modo similar à Chouliaraki e Fairclough (1999) - tipo de linguagem usada para construir uma perspectiva particular sobre um objeto na realidade e o relaciona a modelos mentais ou esquemas - modos particulares de pensar que são socialmente estruturados - oriundos da psicolinguística.

O conceito de esquema tem sido adotado na análise do discurso linguisticamente embasada (por exemplo, Brown e Youle, 1983), e Fairclough $(1989,1992)$ refere-se a essa dimensão cognitiva por 'recursos dos membros'. Neste sentido, Baynham aponta para alguns discursos do letramento tais como 'déficit de pensamento', 'modelo de desenvolvimento de habilidades', 'modelo terapêutico', 'modelo de empoderamento pessoal' e, englobando-os, 'modelos funcionais de letramento' e 'modelos críticos de letramento'.

Um ponto fundamental derivado dessa integração entre análise do discurso linguisticamente embasada e letramento é o fato de que este está encaixado na língua (cf. Barton, 1994; Baynham, 1995), tanto no uso como no sistema da língua. Em relação ao uso do letramento, a noção de discurso como língua em uso, incluindo tanto a linguagem falada como a escrita, explica essa integração em um nível ontológico, isto é, na realidade mesma, quando um/a pesquisador/a investiga o letramento ele/a está investigando o discurso no modo como é desempenhado pelo uso da linguagem escrita. Com relação ao sistema da língua, de acordo com a perspectiva da Linguística Sistêmico-Funcional (LSF), a linguagem escrita é realizada no sistema estratificado da língua e instanciada nas interações concretas, como veremos mais adiante.

Ao combinar abordagens do letramento e do discurso remetome aqui particularmente à Teoria Social do Letramento, como parte dos Novos Estudos do Letramento, e à Análise de Discurso Crítica. Esboço três aspectos que permitem essa integração. Em primeiro lugar, e obviamente, ambas têm um histórico em algum tipo de teoria social (veja, por exemplo, Barton e Hamilton, 1998, 
Cap. 1; Fairclough, 1992, Caps. 2 e 3; Chouliaraki e Fairclough, 1999), no sentido de que paralelamente se preocupam com alguma teorização, respectivamente, do letramento e do discurso em relação às ciências sociais. Em segundo lugar, e como decorrência do primeiro aspecto, ambas enfatizam o fato de que há uma relação inextricável entre língua e prática social. Investigar a língua é uma questão de investigar as práticas com as quais está ligada. Por fim, ambas chamam atenção tanto para a linguagem falada como para a escrita (e outros modos semióticos), e, mesmo se elas aparentemente têm diferentes propósitos de pesquisa, defendo que há um grande potencial para sua integração, tanto teórica como metodologicamente. A esse respeito, vale a pena mencionar alguns trabalhos anteriores, que adotaram essas conexões (Wilson, 1998; Jones, 1999; Tusting, 2000; Keating, 2001; Pitt, 2001). Uma das primeiras abordagens dessa integração concerne a Magalhães (1995) com seu conceito de 'prática discursiva de letramento', que se entende pelas matrizes históricas que determinam a produção e interpretação de instâncias concretas de textos falados ou escritos, com produtores e interlocutores concretos.

Meu interesse específico é traçar similaridades entre os campos do Letramento e da Análise de Discurso Crítica, justapondo modos de fazer pesquisa (métodos), e traduzindo conceitos equivalentes (teoria). Uma notável similaridade, já mencionada acima, é o duplo foco, ou seja, sobre a língua (tradicionalmente no uso da linguagem escrita nos Estudos do Letramento) e sobre (redes de) práticas sociais particulares ocorrentes em instituições, organizações e comunidades (por exemplo, a consulta médico-paciente, reuniões de círculo de qualidade em empresas, usos cotidianos do letramento em contextos locais e assim em diante). Neste sentido, alguns estudos em versões particulares da análise de discurso crítica, as quais têm enfocado diferentes campos institucionais, tais como a burocracia (Sarangi e Slembrouck, 1996) e o discurso técnico (Lemke, 1995), por exemplo, também estão revelando significados sociais em relação aos usos do letramento, ainda que este não seja seu foco principal. 


\section{O Letramento como um elemento discursivo de práticas sociais}

Com relação à teoria, o referencial teórico do discurso de Chouliaraki e Fairclough aponta para uma sofisticada conceitualização do discurso na prática social, que eu penso ser útil para a Teoria Social do Letramento. O discurso, propriamente, é o uso da língua tanto para atuar na vida social como para refletir sobre ela. No interior de uma prática social, o discurso é um elemento que se relaciona dialeticamente com outros, tais como atividades materiais, relações sociais e fenômenos mentais, e nenhum desses elementos se reduzem aos outros, de modo que um interioriza e é interiorizado pelos outros. Como consequência, o letramento nesse referencial faz parte de atividades materiais, tipos de relações sociais e identidades, crenças e valores específicos em uma dada comunidade, bem como contém aspectos desses diferentes elementos. Outra consequência é que os recursos discursivos do elemento discurso no referencial da ADC - gêneros, discursos e estilos, podem ser focalizados na instanciação do letramento, expandindo sobre uma riqueza de possibilidades de combinações entre a fala, a escrita e outros modos semióticos. Assim, pode-se explorar os gêneros escritos, o papel das atividades de leitura e dos textos escritos nos discursos e $\backslash$ ou nos discursos do letramento, se este é o foco, e nos estilos utilizados para a produção de textos. Veja-se a esse respeito que os pontos que serão discutidos adiante sobre intertextualidade e ordens do discurso também se encaixam nessa fusão teórica.

O letramento, amplamente concebido como ato sociocultural concreto constituído por pelo menos uma das seguintes atividades - escrita, leitura e fala ao redor/sobre texto escrito (e também sobre produções semióticas), pode ser traduzido para o interior do referencial de prática social de Chouliaraki e Fairclough, em termos da atividade particular (escrita, leitura e fala ao redor/sobre texto escrito) que se relaciona a categorias tais como valores, redes e 
domínios, que comumente são utilizadas na pesquisa etnográfica do letramento.

$\mathrm{O}$ que eu penso que tem sido problematizado ultimamente nos conceitos de eventos de letramento (cf. Hamilton, 2000) e discurso (cf. Fairclough, 1992; Chouliaraki e Fairclough, 1999) é um entendimento da linguagem escrita ou falada como central e influente em uma prática particular, por exemplo a noção mesma de evento de letramento conforme apresentada por Heath (1983) - eventos em que uma peça de texto é integral - e de Discurso de Gee (1996) - uso da língua que inclui modos de fazer, ser, sentir e assim em diante. Nessas concepções, há dois problemas em potencial. Um é uma possível interpretação em que a linguagem desempenha uma determinação unidirecional, reduzindo os outros elementos da prática social à própria linguagem. $\mathrm{O}$ outro é o fato de que o discurso verbal é distribuído diferentemente no interior das diferentes práticas. Algumas práticas podem recorrer extensivamente, se não somente, a modos semióticos ou sentidos (imagens, olfato, tato), interiorizando o poder semiogenético pela ausência do elemento discursivo verbal. Nesse sentido, defendo que o referencial do discurso multimodal de Kress e van Leeuwen (2001) é bastante válido em conexão com a abordagem da Escola de Lancaster, por evitar o exagero sobre o papel da linguagem e do discurso na prática social.

Portanto, há um problema teórico se se quer articular o conceito de Discurso de Gee com aquele no referencial de Chouliaraki e Fairclough. Gee faz uma equivalência entre a categoria de Discurso e uma associação entre elementos semióticos e não-semióticos da realidade, enquanto Chouliaraki e Fairclough expõem o conceito de prática social como uma categoria em nível superior à do discurso. Particularmente, penso que a consideração do discurso como uma estrutura distintiva nas várias dimensões da vida tem a vantagem de trazer à baila o poder gerador dos sistemas semiótico e linguístico, o que demonstra que a estrutura linguística importa na constituição das práticas sociais. Este é um ponto importante que precisa ficar claro para evitar a subestimação do papel do discurso na dialética complexa entre estrutura e agência. 
A ênfase sobre a identificação do discurso com elementos sociais dá relevância às ordens do discurso mas não à língua como um sistema gramatical, o que sem dúvida é. Por outro lado, a ênfase sobre a identificação do discurso com elementos textuais e linguísticos dá relevância à língua como um sistema gramatical mas não como um sistema de ordens do discurso (ver Chouliaraki e Fairclough, 1999, Cap. 8; Fairclough, 2000).

No entanto, ainda remanescem questionamentos potenciais na relação entre os conceitos de 'prática de letramento' e 'prática social' e isso basicamente se deve à necessidade de mais teorização sobre o que virtualmente está contido no interior das práticas, bem como em que níveis de abstração nós podemos tratá-las. Por exemplo, Pitt (2001) aponta dois sentidos de 'prática' na Teoria Social do Letramento. Um deles é um macrossentido - 'práticas de letramento como modos culturais de usar o letramento', e o outro é um microssentido - 'o letramento compreendido como uma série de práticas sociais'. É particularmente o último sentido que torna a integração entre os referenciais da $\mathrm{ADC}$ e da TSL problemática.

Vejo a noção de 'letramento' posicionada no mesmo nível de abstração da noção do discurso, de modo que o predicado 'série de práticas sociais' instaura uma contradição que reside na identificação de uma categoria em nível inferior - letramento ou discurso - com uma em um nível superior - a categoria da prática. Essa contradição conceitual refere-se tanto à redução de qualquer elemento da prática social aos outros, como à redução da própria prática ao elemento do discurso.

Ainda assim, o conceito de 'evento de letramento' e o referencial teórico do discurso estão inerentemente um no outro, e isso pode ser visto no uso da linguagem escrita ou na construção reflexiva do (dos significados que implicam o) letramento e dos letramentos. É nesse sentido que utilizo a expressão 'discursos do letramento'. 'Letramento' não é somente um modificador de 'discursos', essa expressão deve ser entendida como um nome composto para enfatizar que o que está sendo estudado é tanto a linguagem escrita como atividade quanto sua representação pelos participantes da pesquisa. Além disso, prefiro essa 
expressão no lugar de 'práticas de letramento' no microssentido, a fim de evitar a incompatibilidade discutida acima entre os referenciais teóricos da ADC e da TSL.

Um aspecto importante da integração entre os conceitos de letramento e do discurso é que a existência dupla do discurso como atividade e reflexividade entra no conceito de evento de letramento. Assim, poderíamos construir uma distinção entre atividades e narrativas nos Estudos do Letramento (ver Baynham, 2000, sobre narrativas). Essas narrativas são recontextualizações de eventos passados que trazem em si um elemento de reflexividade.

\section{Etnografia, letramento, discurso e gramática funcional}

Outro ponto importante na integração teórica entre os Novos Estudos do Letramento e a Análise de Discurso Crítica reside precisamente no encontro entre a face epistemológica da etnografia e as noções de contexto e prática social na ADC. A etnografia e a ADC frequentemente se coincidem na investigação do contexto situacional, institucional e societário, embora a análise textual e interdiscursiva geralmente não tenha sido uma preocupação para a etnografia no passado. Tanto o contexto como a prática social envolvem o texto e a língua em uma configuração bastante amarrada, o que não devemos perder de vista. Abaixo, ofereço uma alternativa para mapear essa configuração: 


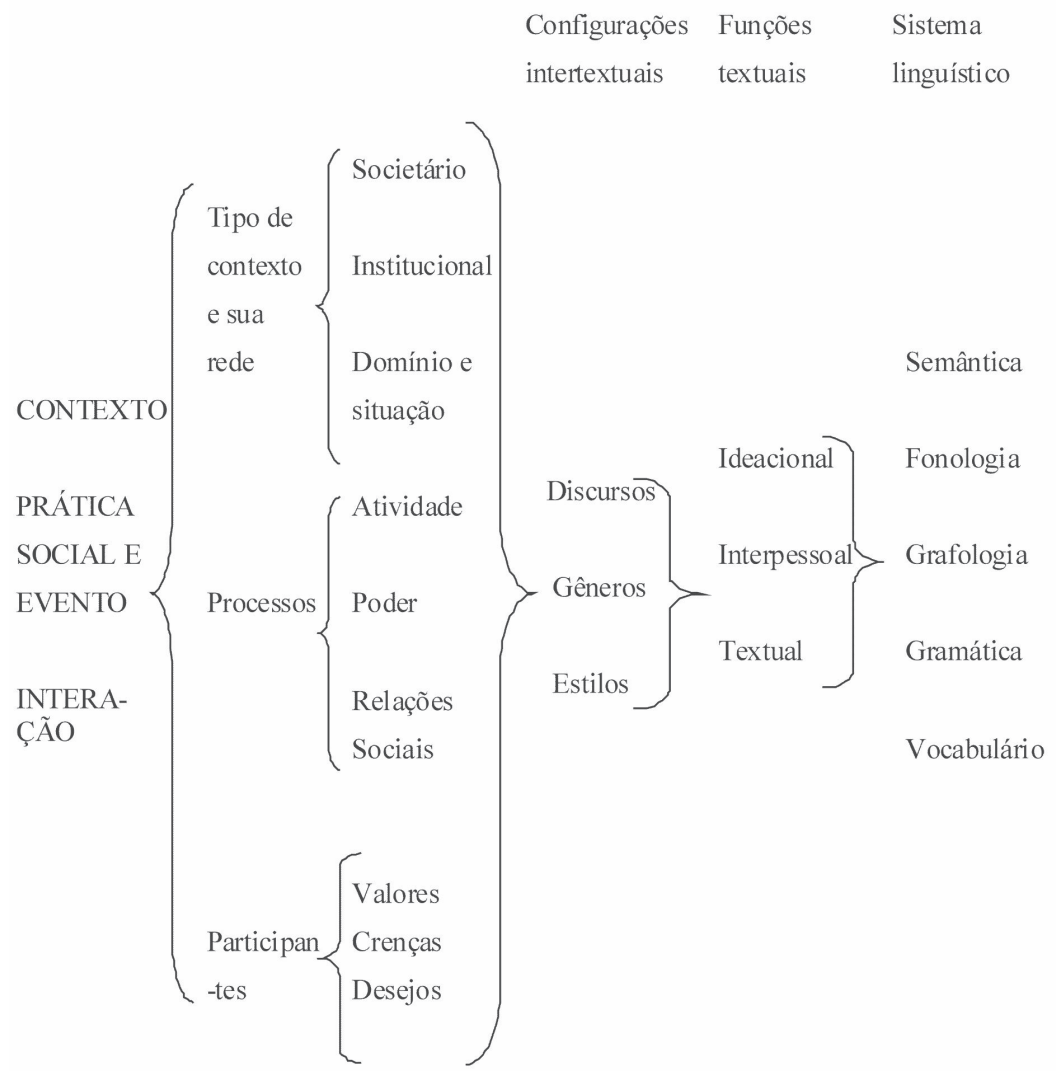

Figura 1 - Configuração abstrata do contexto à prática social

O diagrama apresentado na Figura 1 baseia-se numa ampla descrição de contexto e prática social na Antropologia, a qual tem suas raízes em Malinowski (1922), na tradição de estudos etnográficos do letramento (Street, 1995; Barton e Hamilton, 1998) e nos construtos da LSF (Halliday e Hasan, 1985; Halliday, 1994) e na ADC (Fairclough, 1992; Chouliaraki e Fairclough, 1999). Enquanto as categorias sociais de tipo de contexto, processos e participantes desdobram-se nas subcategorias acima, as categorias de língua, texto e discurso desdobram-se em tudo o que segue. A consideração feita aqui é que 
cada elemento linguístico, textual e do discurso é um contribuinte, em maior ou menor grau, para as subcategorias e categorias no contexto e na prática social. Essa ideia se harmoniza com a noção dialética sobre a interação no interior dos recursos discursivos e entre o discurso e os outros elementos da prática social, conforme visto acima.

É relevante mencionar aqui que a LSF proveu parte do referencial teórico para a análise textual e linguística no interior da ADC nos anos recentes. Chouliaraki e Fairclough (1999) propõem que a ADC complementa e expande a LSF (Halliday, 1994, Martin, 1997), a qual por sua vez apresenta uma visão de língua multifuncional (ou multissignificativa) e socioestruturante. É multifuncional no mesmo modo como na tradição inaugurada por Malinowski de conceber a função em relação ao significado em um contexto de situação particular. Halliday e Hasan (1985) derivaram três aspectos da noção de contexto de situação: campo do discurso, tenor do discurso e modo do discurso. Campo se refere aos processos sociais e sua natureza, que ocorrem no ambiente imediato, de acordo com os quais a língua exerce um trabalho particular. O tenor refere-se ao papel dos participantes e suas relações nos processos, sempre em relação aos tipos de papel do discurso sendo representado. $\mathrm{O}$ modo se refere ao papel específico da língua em termos das ações que são esperadas, os significados que podem ser extraídos da organização textual, o status do texto, se é falado ou escrito e o modo retórico concebido em termos de ser persuasivo, expositivo, didático etc.

Primeiramente, a língua neste referencial teórico é funcional não só devido a seu uso em um contexto de situação, mas também porque função é em si mesma uma propriedade do sistema da língua. $\mathrm{O}$ aspecto central desta teoria é a língua como uso e sistema, para construir significado. O significado no contexto, mais do que a forma das unidades linguísticas, é o ponto de chegada dentro de uma abordagem funcional da língua. Tal abordagem traz à tona o conceito de texto como uma unidade que recorre a estruturas na gramática para produzir significados de acordo com cada um dos três aspectos do contexto de situação. Ou seja, estruturas gramaticais, tais como transitividade e nomeação estão associadas à representação do mundo 
por meio de nossas experiências (significados experienciais), e por isso estão associadas ao campo do discurso. Por sua vez, tipos oracionais, modalidade e pessoa estão associados às relações pessoais que estão envolvidas na interação (significados interpessoais) e ao tenor do discurso. Por fim, o tema, a estrutura da informação e as relações coesivas estão associadas à textura (significados textuais) e ao modo do discurso.

Há outro aspecto do significado neste referencial teórico - o significado lógico - que está relacionado à hierarquia das relações lógicas entre um processo e outro, ou entre um participante e outro. Essas relações lógicas são expressas na gramática por meio de diferentes formas de parataxe (coordenação) e hipotaxe (subordinação).

Esses significados discutidos acima estão condensados em três metafunções, as quais são os componentes fundamentais do significado (Halliday, 1994). Os significados experiencial e lógico compreendem a metafunção ideacional, e por eles se entende como as características linguísticas funcionam na representação de processos e participantes à medida que engajamos em experiências de vida. Os significados interpessoal e textual, em seguida, são designados respectivamente as metafunções interpessoal e textual. O primeiro tem a ver com a ação intencionada e esperada no interior das relações entre participantes, ao passo que o segundoo é o que dá relevância às metafunções ideacional e interpessoal.

A língua como um sistema é feita de estratos, dentre os quais há o semântico, o fonológico, o grafológico e o léxico-gramátical. O estrato semântico refere-se ao estrato do significado, e o fonológico e grafológico, ao estrato da expressão. Ambos têm referência extralinguística, uma vez que ideias, conceitos, objetos, disposições corporais, sons da fala e a escrita estão associadas a significados e expressões. O estrato léxico-gramatical, que não está diretamente relacionado ao extralinguístico, medeia a ligação entre os estratos do significado e da expressão (Halliday, 1961, cf. Chouliarai e Fairclough, 1999).

$\mathrm{Na}$ linguística sistêmico-funcional, a língua é estruturada e estrutura o social, ou seja, os significados ideacional, interpessoal e 
textual são, por um lado, instanciados por meio de recursos no interior do estrato léxico-gramatical no uso da língua, e, por outro lado, eles são realizados por meio de uma série de recursos potenciais no sistema da língua. Essa série de possibilidades disponível como escolhas na língua é o que dá à teoria a propriedade de ser sistêmica.

\section{Considerações finais: implicações}

Aqui, quero explorar duas implicações (obviamente pode haver outras) para a pesquisa sobre o letramento, derivada da integração entre os Estudos do Letramento e os Estudos do Discurso. Em primeiro lugar, há maior ênfase na análise e consciência da manifestação da língua e da semiose em instâncias particulares, tais como 1) textos, conversação e artefatos produzidos nas atividades sob estudo; 2) relatos dos participantes dos eventos de letramento gerados por meio de entrevistas de pesquisa; 3) anotações, fotografias e vídeos, todos produzidos a partir da observação desses eventos.

Isso não significa que uma única pesquisa do letramento baseada no discurso deveria incluir todos esses tipos de dados. Obviamente, há antes uma dimensão discricionária, ou seja, cabe ao(à) pesquisador(a) decidir quais são as fontes de dados mais importantes para sua própria pesquisa. Além disso, a contingência empírica, isto é, a realidade encontrada durante o trabalho de campo (a parte "bagunçada" da pesquisa), precisa ser levada em consideração, uma vez que a praticabilidade da coleta de dados também afetará as questões de pesquisa planejadas, trazendo o processo de pesquisa para um redesenho e possivelmente para uma nova pesquisa.

A segunda implicação deriva da integração teórica entre a etnografia e a ADC, conforme discutido na seção prévia. Há uma distinção importante entre o uso situado do letramento e a linguagem usada em textos nessas situações particulares. Uma visão do discurso habilita pesquisadores(as) a fazer conexões entre o contexto situacional, institucional ou societário (cf. Fairclough, 1992) - e o texto, por meio da análise de como os processos contextuais e os 
participantes são representados nos textos (van Leeuwen, 1995, 1996). O ponto-chave aqui é o pressuposto de que os elementos linguísticos estão amarrados a elementos mais amplos das prática sociais e, indiretamente, das estruturas sociais, o que reforça o chamado de Fairclough para uma escolha transdisciplinar sobre a questão da pesquisa social que envolve a linguagem. Vale a pena relembrar seus argumentos em um trabalho anterior (Fairclough, 1995: 208-209). Inicialmente, Fairclough assevera que não é o caso de unificar a prática analítica dentre diferentes teorias, métodos e abordagens, mas buscar algum consenso sobre as questões teóricas e metodológicas principais no campo de estudo. Assim, propõe ele que a natureza dos textos e a análise textual são significativas. Fairclough sugere quatro razões para um amplo reconhecimento da análise textual no interior de um referencial teórico de análise do discurso e como parte dos recursos metodológicos das ciências sociais. A primeira uma razão teórica - relaciona-se à ideia da dialética entre estrutura e agência na vida social: os textos são uma forma importante de ação social, e por isso não deveriam ser ignorados. A segunda - uma razão metodológica - é que os textos como uma forma de ação provêm evidência para fundamentar proposições sobre estruturas, relações e processos sociais. A terceira - uma razão histórica - refere-se ao fato de que os textos provêm evidências de processos que estão em curso, tais como a redefinição de relações sociais entre profissionais e o público, a reconstituição de identidades sociais e formas do "eu", e do conhecimento e da ideologia. Por fim - uma razão política é que a análise textual como parte da análise do discurso pode ser um recurso político importante para criticar o controle e a dominação social exercida por meio de textos. Neste sentido, ela favorece esforços em direção a uma consciência crítica da linguagem.

Portanto, em termos de método, onde a pesquisa sobre o uso do letramento está sendo conduzida vale a pena analisar textos. A configuração particular da linguagem e dos textos pode oferecer detalhes importantes para o entendimento das atividades que estão sendo representadas ou narradas, aperfeiçoando ainda mais a análise conduzida nos estudos do letramento. Por exemplo, algumas partículas 
modais e tempo verbal no presente podem ser úteis para impingir autoridade sobre o que está sendo dito, significando a posição de poder da qual o(a) falante diz, ou sua convicção sobre o que é dito; o gênero argumentativo veicula alguma forma de raciocínio, que pode indicar a racionalização de valores e pressupostos - ideológica ou não - pelos participantes da pesquisa.

As metodologias etnográficas tradicionalmente adotadas nos estudos do letramento podem ser uma parte complementar da pesquisa em análise do discurso, particularmente aquela empreendida no interior de uma visão processual do texto, ou seja, o texto como um processo que se desdobra no tempo-espaço. Como uma linha importante na $\mathrm{ADC}$, os textos funcionam nos processos das atividades produzindo a vida social. Isso implica uma tarefa de análise textual que não reduza o discurso nem os elementos sociais, mas que os coloque juntos no elemento do discurso, que tem uma estrutura dupla de poderes geradores: sistemas semióticos (que incluem a linguagem verbal) e as ordens do discurso. O poder do semiótico é sua capacidade ilimitada de construir significado por meio de relações sintagmáticas e paradigmáticas. O poder das ordens do discurso é sua capacidade ilimitada de construir significados por meio de novas articulações entre discursos, gêneros e estilos. Resumindo, os elementos sociais se encaixam em ambas as estruturas do semiótico - as ordens do discurso e os sistemas semióticos - e a análise de texto não deve perdê-las de vista (Fairclough, 2001). Nesse referencial teórico, os elementos sociais, relacionados aos processos sociológicos, psicológicos e culturais, precisam ser incorporados à pesquisa desde o início de seu planejamento. Essa é a razão por que notas de campo, diários, entrevistas e outros tipos de documentação auxiliam a relacionar práticas textuais a seus elementos sociais e às suas respectivas redes de práticas sociais mais amplas; elas auxiliam o entendimento do contexto de produção textual. Penso que essas proposições possam contribuir para a pesquisa em curso no Brasil, que relaciona os campos tratados neste trabalho. 


\section{Referências bibliográficas}

BARTON, D. Literacy: an introduction to the ecology of written language. Oxford, U.K. and Cambridge, U.S.A.: Blackwell, 1994.

BARTON, D. \& HAMILTON, M. Local literacies. London: Routledge, 1998. . "Literacy practices". In D. Barton, M. Hamilton, \& R. Ivanic (eds.) Situated Literacies. London: Routledge, 7-15, 2000.

BAYNHAM, M. "Code switching and mode switching: community interpreters and mediators of literacy”. In: B. Street. Cross-cultural approaches to literacy. Cambridge: Cambridge University Press, 294-314, 1993. . Literacy practices. London: Longman, 1995.

. "Narrative as evidence in literacy research". Linguistics andEducation 11 (2), 99-117, 2000.

BROWN, G. \& YULE, G. Discourse analysis. Cambridge: Cambridge University Press, 1983.

CHOUlIARAKI, L. \& FAIRCLOUGH, N. Discourse in late modernity. Edinburgh: Edinburgh University Press, 1999.

FAIRCLOUGH, N. Language and power. London: Longman, 1989.

FAIRCLOUGH, N. Discourse and social change. Cambridge: Polity Press, 1992. . Critical Discourse Analysis. London: Longman, 1995.

FAIRCLOUGH, N. "Multiliteracies and language". In B. Cope \& M. Kalantzis. Multiliteracies. London: Routledge, 2000.

FAIRCLOUGH, N. Language, Ideology and Power Research Group Seminar on Text Analysis. Manuscript, 2001.

GEE, J. Social linguistics and literacies: ideologies in discourses. Basingstoke: The Falmer Press, Taylor and Francis Inc., 1990.

HALLIDAY, M.A.K. "Categories of the theory of grammar". Word 17, 1961. HALLIDAY, M.A.K. Introduction to functional grammar, $2^{\text {nd }}$ edn, London: Edward Arnold, 1994.

HALLIDAY, M.A.K. \& HASAN, R. Language, context and text. Aspects of 
language in a social semiotic perspective. Oxford: Oxford University Press, 1985.

HAMILTON, M. "Expanding the new literacy studies: using photographs to explore literacy as social practice”. In D. Barton, M. Hamilton, \& R. Ivanic (eds.) Situated Literacies. London: Routledge, 16-34, 2000.

HEATH, S. B. Ways with words: language, life and work in communities and classrooms. Cambridge: Cambridge University Press, 1983.

KEATING, M.C. Routes through literacy: The lived experiences with literacy of Portuguese women in London. Unpublished Ph.D. thesis, Linguistics Department, Lancaster University, 2001.

KRESS, G. Linguistic processes in sociocultural practice. Oxford: Oxford University Press, 1989.

KRESS, G. \& VAN LEEUWEN, T. Multimodal discourse. London: Edward Arnold, 2001.

LEMKE, J. Textual politics. London: Taylor \& Francis, 1995.

MAGALHÃES, I. "Práticas discursivas de letramento: a construção da identidade em relatos de mulheres”. In A. Kleiman (org.) Os significados do letramento: uma nova perspectiva sobre a prática social da escrita. Campinas, S.P: Mercado de Letras, 201-235, 1995.

MALINOWSKI, B. Argonauts of the Western Pacific. London: Routledge, 1922.

MARTIN, J. "Analysing genre: functional parameters." In F. Christie \& J. Martin (ed.) Genre and institutions. Social processes in the workplace and school. London: Cassell, 3-39, 1997.

PITT, K. The discourse of family literacy. Unpublished Ph.D. thesis, Linguistics Department, Lancaster University, 2001.

RIOS, G. Literacy discourses: a sociocultural critique in Brazilian communities. Saarbrücken: Verlag Dr Müller, 2009.

SARANGI, S. \& SLEMBROUCK, S. Language, bureaucracy and social control. London: Longman, 1996.

STREET, B. Literacy in theory and practice. Cambridge: Cambridge University Press, 1984.

(ed). Cross-cultural approaches to literacy. Cambridge: Cambridge 
University Press, 1993.

Social literacies. London: Routledge, 1995.

TUSTING, K. Written intertextuality and the construction of catholic identity in parish community: an ethnographic study. Unpublished Ph.D. thesis, Linguistics Department, Lancaster University, 2000.

VAN LEEUWEN, T. "Representing social action". Discourse \& Society 6 (1), 81-106, 1995.

VAN LEEUWEN, T. "The representation of social actors". In: Carmen R. Caldas-Coulthard \& Malcolm Coulthard. Eds.. Texts and Practices. London/ New York: Routledge, 32-70, 1996.

WILSON, A. Reading a library-writing a book: the significance of literacies for the prison community. Unpublished Ph.D. thesis, Linguistics Department, Lancaster University, 1998.

Recebido em: julho de 2010 Aprovado em: setembro de 2010 g.veigarios@gmail.com 